SOUSA, M.R.Q. e SILVA, F.B.S. Interação homem-animal e sua relação com a guarda responsável de cães em um bairro da cidade do Recife-PE. PUBVET, Londrina, V. 6, N. 5, Ed. 192, Art. 1294, 2012.

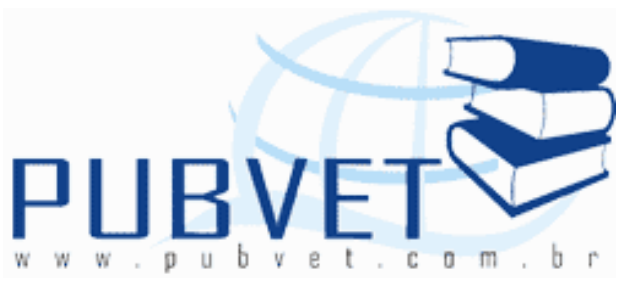

PUBVET, Publicações em Medicina Veterinária e Zootecnia.

\title{
Interação homem-animal e sua relação com a guarda responsável de cães em um bairro da cidade do Recife-PE
}

Maria Raquel Querino de Sousa ${ }^{1}$ e Fabíola Braz de Sousa Silva ${ }^{2}$

${ }^{1}$ Médica Veterinária, Professora de Fisiologia Animal, Universidade Federal Rural de Pernambuco. Rua Dom Manoel de Medeiros, s/n, Dois Irmãos - CEP: 52171-900 - Recife/PE. E-mail: raquel.ufrpe@gmail.com.

${ }^{2}$ Bióloga, Agente Comunitária de Saúde, Recife-PE

\section{Resumo}

Os cães, como animais de companhia, têm desempenhado importante papel na sociedade atual, ocupando posições antes exclusivas dos seres humanos. $O$ crescimento populacional desses animais, no entanto, trouxe vários problemas devido ao grande número de cães errantes nas grandes cidades, acarretando riscos à saúde pública pela disseminação de zoonoses e por ataques agressivos à comunidade. Tal problema é consequência direta das práticas de seus tutores e reflexo do nível educacional dos mesmos. Com o objetivo de se conhecer a realidade local do Alto José do Pinho, um populoso bairro da Cidade do Recife-PE (229,6 hab/ha), foi realiza uma pesquisa por meio de entrevistas aplicadas por Agentes Comunitários de Saúde (ACS) do bairro a 240 moradores, proprietários de pelo menos um cão por residência. No inquérito, foram coletadas informações sobre nutrição, cuidados com a saúde, lazer, controle de natalidade e recolhimento das fezes dos animais. Os resultados 
SOUSA, M.R.Q. e SILVA, F.B.S. Interação homem-animal e sua relação com a guarda responsável de cães em um bairro da cidade do Recife-PE. PUBVET, Londrina, V. 6, N. 5, Ed. 192, Art. 1294, 2012.

mostraram a necessidade de programas oficiais para educação em guarda responsável que melhorem a interação homem-animal, o bem-estar desses animais e a saúde pública em geral.

Palavras-chave: Interação homem-animal, bem-estar animal, guarda responsável, saúde pública.

\title{
Human-animal interaction and its relation to responsible dog ownership in a district of Recife-PE
}

\begin{abstract}
Dogs as companion animals have played an important role in the actual society thus occupying place only done by humans. However, population growth of these animals brought various problems caused mainly by wandering dogs in big towns, which cause risks of health hazard and aggressive attacks. Such problems are direct reflex of the behavior of owner practice, whose default in regard to ownership responsibility and animal welfare. In order to know the local reality at Alto Jose do Pinho, a populous district $(229,6$ inhab/ha) of Recife-PE, a survey was carried out to 240 residents owners at least one dog per residence. The survey was applied by Community Health Agents ( $\mathrm{CHA})$ and data about nutrition, health care, leisure, birth control and animal feces collect. The collected data indicated a necessity of official programs of education for responsible ownership and improvement of man-animal interaction, animal welfare and public health.
\end{abstract}

Keywords: human-animal interaction, animal welfare, responsible ownership, public health.

\section{INTRODUÇÃO}

Os cães se destacam cada vez mais na sociedade atual, onde desempenham diversas atividades e ocupam posições até então exclusivas dos seres humanos. De companheiros que compartilham os espaços e a vida das 
SOUSA, M.R.Q. e SILVA, F.B.S. Interação homem-animal e sua relação com a guarda responsável de cães em um bairro da cidade do Recife-PE. PUBVET, Londrina, V. 6, N. 5, Ed. 192, Art. 1294, 2012.

pessoas até colaboradores nas divisões policiais, os cães são os animais que mais têm se aproximado do homem. Se por um lado, a mudança de status dos cães trouxe benefícios para sua qualidade de vida com investimentos nas indústrias alimentícias e farmacêuticas, por outro, o aumento no número de cães tem contribuído para agravar um problema crônico, especialmente nas grandes cidades, que é a presença de animais soltos em locais públicos.

Dados da Maps of World ${ }^{1}$ apontam o Brasil com a $2^{a}$ maior população de cães do mundo, com um total de 30.051 .000 animais. Estes dados representam uma grande preocupação para as autoridades, pois se sabe que este aumento não é proporcional ao investimento em educação em guarda responsável pelos órgãos competentes. Disto resulta que a falta de informação e responsabilidade por parte dos tutores de cães tem tido como consequência transtornos sanitários e ambientais, além do comprometimento do bem-estar dos animais.

O aumento do número de cães errantes é um reflexo direto das práticas de seus tutores. O comportamento humano possivelmente é a força mais poderosa por trás da dinâmica da população canina e o estímulo para interação homem-animal de forma responsável levará a melhora do bem-estar animal e a redução de muitas das origens de cães de rua (Aliança ICAM, 2007)2.

Segundo a Organização Mundial de Saúde $(1990)^{3}$, os métodos tradicionais empregados pelos órgãos responsáveis para controle da população canina, que a remoção dos animais seguida do sacrifício dos mesmos, não resolve o problema a menos que sejam combinados com outros métodos como identificação dos animais, esterilização dos mesmos e educação da população.

A organização mundial de sanidade animal (OIE, 2010) ${ }^{4}$ relata que a promoção da guarda responsável possa reduzir significativamente o número de cães e a incidência de zoonoses. Entretanto, o efetivo controle da população canina só é possível se houver mudanças no comportamento dos tutores dos animais. Ainda segundo a OIE (2010), a propriedade responsável de um cão designa a situação em que uma pessoa aceita e se compromete a cumprir uma série de obrigações demandas pela legislação vigente, visando satisfazer as 
SOUSA, M.R.Q. e SILVA, F.B.S. Interação homem-animal e sua relação com a guarda responsável de cães em um bairro da cidade do Recife-PE. PUBVET, Londrina, V. 6, N. 5, Ed. 192, Art. 1294, 2012.

necessidades comportamentais, ambientais e físicas de um cão e a prevenir riscos (agressão, transmissão de doenças ou feridas) que o animal possa representar para a comunidade, para outros animais ou para o meio.

Segundo Luna (s.d.) ${ }^{5}$ educar as pessoas para a importância da guarda responsável dos animais, envolve o fato que os animais devem ser mantidos dignamente em boas condições de abrigo, alimentação e saúde, nos limites da propriedade de cada dono.

Com o objetivo de conhecer a realidade local e, assim, desenvolver programas educativos em guarda responsável, foi realizada uma pesquisa sobre as concepções e práticas de tutores de cães em um Bairro da cidade do Recife-PE,

\section{MATERIAL E MÉTODO}

O local de realização da pesquisa foi o bairro Alto José do Pinho, localizado na zona norte da cidade do Recife-PE, com área geográfica de 41,5 ha e densidade populacional de 229,57 habitantes/ha (Prefeitura da cidade do Recife, 2011) ${ }^{6}$.

A pesquisa foi realizada em julho de 2009, através de entrevistas feitas por Agentes Comunitários de Saúde (ACS) do bairro, com 240 moradores que possuiam pelo menos um cão em sua residência. Foi utilizando um questionário contendo perguntas, envolvendo temas variados relativos a guarda responsável e bem-estar de cães. Algumas perguntas foram feitas sem oferecer alternativas de respostas aos pesquisados, e, posteriormente, as respostas foram agrupadas em categorias de acordo com a pertinência, e para outras foram oferecidas alternativas de sim e não.

Para melhor conhecer a realidade do tema guarda responsável na comunidade, foram abordadas questões sobre os cuidados com o animal, tais como, higiene, alimentação, vermifugação, vacinação, lazer do animal e controle da natalidade, além das atitudes em relação ao recolhimento de suas fezes. 
SOUSA, M.R.Q. e SILVA, F.B.S. Interação homem-animal e sua relação com a guarda responsável de cães em um bairro da cidade do Recife-PE. PUBVET, Londrina, V. 6, N. 5, Ed. 192, Art. 1294, 2012.

As informações obtidas pelas respostas das entrevistas serviram de base para orientação dos tutores dos animais, que foi realizada pelos Agentes Comunitários de Saúde, envolvidos no projeto e treinados previamente.

\section{RESULTADOS E DISCUSSÃO}

Constatou-se que $89,6 \%$ dos entrevistados afirmaram que todos os membros da família aceitavam o animal em sua residência. Este dado foi bastante relevante, pois se sabe que os maus-tratos e abandonos são resultantes, muitas vezes, da não concordância com a presença do animal por alguns membros da família. As rejeições encontradas foram justificadas devido a casos de alergia na família ou por não gostarem da espécie. Sabemos que a aquisição de um animal quando feita de forma impulsiva, motivada por diversos fatores e sem a consciência das necessidades do animal e do compromisso com sua educação, acarreta, muitas vezes, em abandono quando o animal apresenta comportamentos indesejados ou fica doente. A educação em guarda responsável deve ter também um caráter preventivo, pois a aquisição de um animal implica na mudança dos hábitos de uma família por diversos anos. Ainda tem-se que considerar que as condições de manutenção de um animal de estimação envolvem a interação e participação dos vários membros da família, além de custos financeiros.

Em relação à motivação para aquisição dos animais, a grande maioria dos entrevistados $(92,5 \%)$, como pode ser observado na figura 1 , citou a companhia e a amizade como os principais motivos para terem um animal em sua residência. Pesquisas em outros municípios brasileiros, também encontraram a companhia como a principal motivação para aquisição de cães (Pinheiro Junior et al., 2006 ${ }^{7}$; Silva et al., 20098). Faraco $(2008)^{9}$ cita que um dos benefícios da presença de animais na vida das pessoas é a sua companhia, sendo os cães, gatos e cavalos referidos como "animais de companhia" por estabelecerem fortes vínculos emocionais recíprocos com os humanos. 
SOUSA, M.R.Q. e SILVA, F.B.S. Interação homem-animal e sua relação com a guarda responsável de cães em um bairro da cidade do Recife-PE. PUBVET, Londrina, V. 6, N. 5, Ed. 192, Art. 1294, 2012.

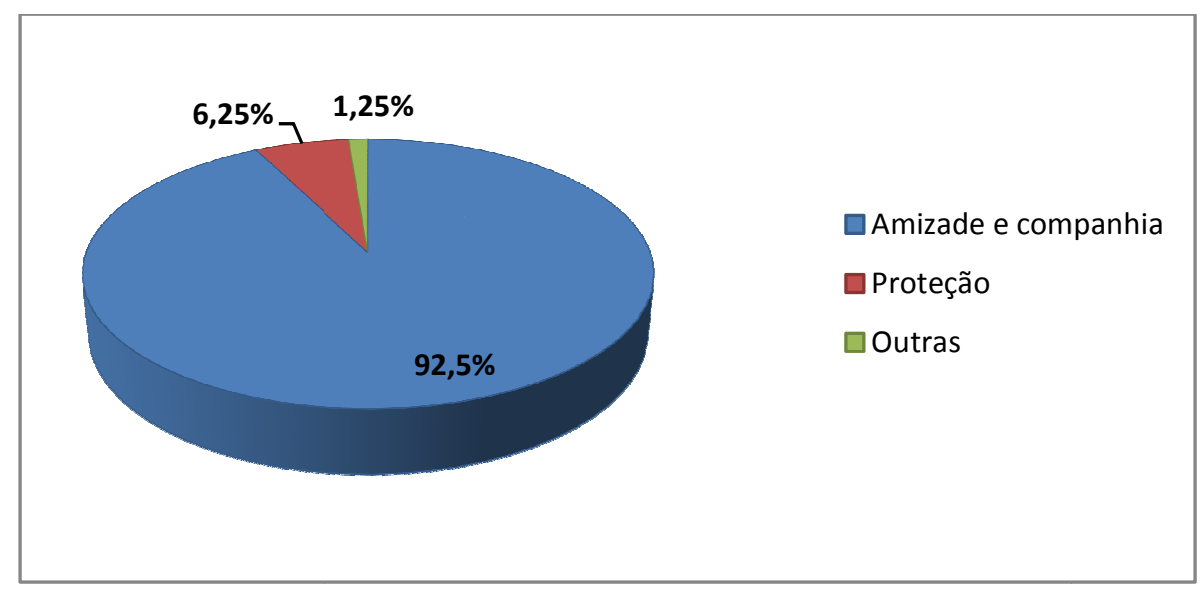

Figura 1 - Motivos que justificam a convivência com os cães

Em relação ao local onde os animais vivem, verificamos que $60,4 \%$ dos entrevistados afirmaram que os cães passam maior parte do seu tempo no quintal e $30,0 \%$ dentro de casa. Foi observado que a maioria dos cães que ficam dentro de casa pertence a raças de pequeno porte como, por exemplo, Poodle, os quais, aparentemente, são mais bem-tratados. Os cães que ficam no quintal circulam, também, dentro de casa. Os que vivem exclusivamente no quintal são aqueles empregados para proteção da residência.

Aproximadamente $10 \%$ dos tutores afirmaram deixar seus cães a maior parte do tempo na rua, alegando que "...os animais se sentem mais livres e já estão bastante acostumados a ficar na rua, sendo mais fácil uma pessoa sofrer um acidente do que os cães". Este tipo de comportamento apresentado pelos tutores é bastante comum, porém inadequado e preocupante, uma vez que o animal pode contrair ou transmitir doenças, especialmente zoonoses, ser agredido ou agredir outros animais e pessoas, além de poderem causar acidentes de trânsito. Além destes problemas, têm-se as questões sanitárias e ambientais envolvidas devido aos dejetos deixados no ambiente, como, por exemplo, transmissão direta de doenças, desenvolvimento de insetos que podem ser vetores de outras doenças e poluição ambiental.

Considerando a relevância da atitude de deixar os animais soltos nas ruas, foi questionado se os animais que ficam em outros ambientes também 
SOUSA, M.R.Q. e SILVA, F.B.S. Interação homem-animal e sua relação com a guarda responsável de cães em um bairro da cidade do Recife-PE. PUBVET, Londrina, V. 6, N. 5, Ed. 192, Art. 1294, 2012.

saem às ruas. Verificou-se que $72,5 \%$ dos entrevistados disseram que não deixam o seu cão só na rua, porém algumas pessoas afirmaram que ao saírem sozinhos os cães ficam apenas na frente da residência em que vivem.

Para garantir o bom nível de bem-estar de um animal, o responsável pelo mesmo deve alimentá-lo adequadamente, cuidar de sua saúde física e emocional, além de permitir que o mesmo expresse seus comportamentos naturais. A alimentação com ração é a melhor escolha, pois o animal irá encontrar todos os nutrientes necessários a manutenção de suas funções biológicas.

Os resultados para as questões que forneceram como alternativas de respostas "sim" ou "não" estão representados na tabela 1.

Tabela 1 - Respostas que avaliam as atitudes dos tutores em relação a saúde, higiene e lazer dos animais.

\begin{tabular}{l|c|c}
\hline \multirow{2}{*}{ ATITUDES DOS TUTORES } & \multicolumn{2}{|c}{ RESPOSTAS } \\
\cline { 2 - 3 } & Sim & Não \\
\hline \hline O animal se alimenta apenas com & $5 \%$ & $95 \%$ \\
ração & $20 \%$ & $80 \%$ \\
O animal é levado para passear & & $23 \%$ \\
todos os dias? & $77 \%$ & $44 \%$ \\
O animal toma banho pelo menos & $56 \%$ & $2 \%$ \\
a cada 15 dias? & $98 \%$ & $98 \%$ \\
O animal é vermifugado? & $2 \%$ & \\
O animal é vacinado? & & \\
O animal é castrado? & & \\
\hline
\end{tabular}

Como verificado na tabela 1 , apenas $5 \%$ dos tutores informaram que seu animal se alimenta apenas de ração enquanto $64 \%$ afirmaram que os animais têm uma alimentação mista, que inclui ração e restos de comida caseira. Quando o responsável pelo animal substitui a ração, parcial ou totalmente, por comidas caseiras, o animal pode apresentar desnutrição, excesso de peso ou outros alterações metabólicas. Salzo \& Larsson $(2009)^{10}$ constaram que a 
SOUSA, M.R.Q. e SILVA, F.B.S. Interação homem-animal e sua relação com a guarda responsável de cães em um bairro da cidade do Recife-PE. PUBVET, Londrina, V. 6, N. 5, Ed. 192, Art. 1294, 2012.

carne bovina, carne de frango e arroz estavam envolvidos na maioria dos casos de hipersensibilidade alimentar em um grupo de cães estudados.

Sair para passear diariamente com o animal possibilita ao mesmo ter contato com cheiros novos, exercitar seu comportamento de marcação e gastar energia, reduzindo assim o nível de estresse, devido ao confinamento, além de aumentar o vínculo entre o tutor/ responsável e o seu animal. Verificou-se, porém, que apenas $20 \%$ dos tutores (tabela 1 ) têm o hábito de sair com seu animal.

Em relação aos cuidados com a saúde dos animais, verificou-se um resultado satisfatório para o quesito vacinação (tabela 1 ), entretanto, quando foi perguntado onde costumam vacinar os animais, $68 \%$ dos tutores afirmaram vacinar somente nas campanhas públicas, que inclui apenas a vacina antirábica. Este resultado mostra a necessidade da inclusão de outras doenças na relação das vacinas gratuitas. Resultados semelhantes para vacinação foram verificados por Cunha et al (s.d.) ${ }^{11}$ que verificaram cobertura vacinal para raiva de $62,5 \%$ em um bairro de Betim (MG).

A falta de vermifugação dos animais, verificada através da pesquisa (tabela 1) também é um dado preocupante, haja vista que várias zoonoses podem ser transmitidas pelas fezes. Aos tutores que afirmaram vemifugar seus animais, questionou-se onde e como era feito este tratamento. A maioria afirmou que eles mesmos administram medicamentos de uso humano, distribuídos no posto médico. Assim sendo, pode-se inferir que o tratamento, em sua maioria, não seja eficaz.

O local onde os animais, comumente, defecam e a atitude dos tutores em relação ao recolhimento das fezes foram também investigados e os resultados podem ser verificados nas figuras 2 e 3 . 
SOUSA, M.R.Q. e SILVA, F.B.S. Interação homem-animal e sua relação com a guarda responsável de cães em um bairro da cidade do Recife-PE. PUBVET, Londrina, V. 6, N. 5, Ed. 192, Art. 1294, 2012.

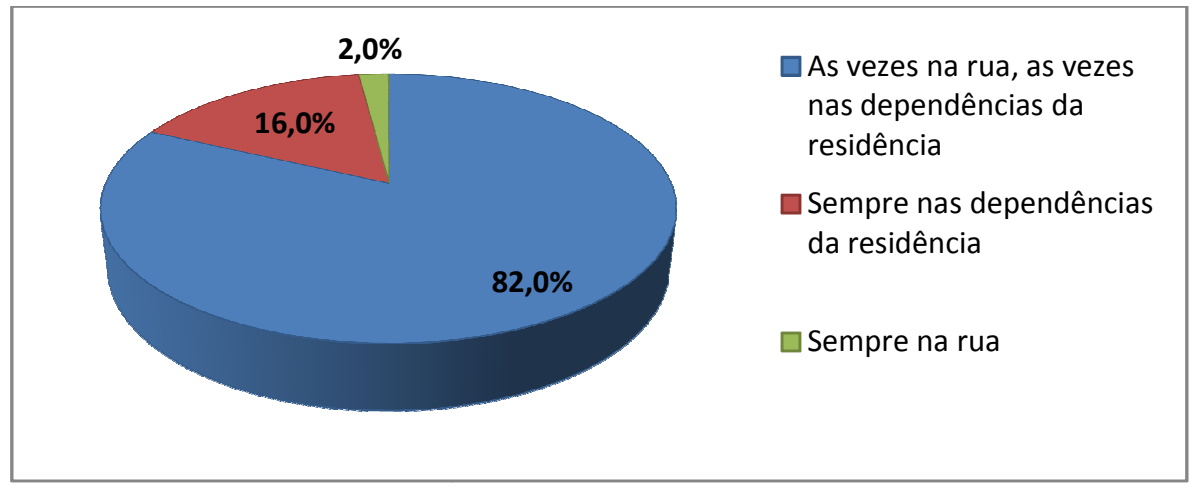

Figura 2 - Locais onde os animais, defecam, segundo seus tutores.

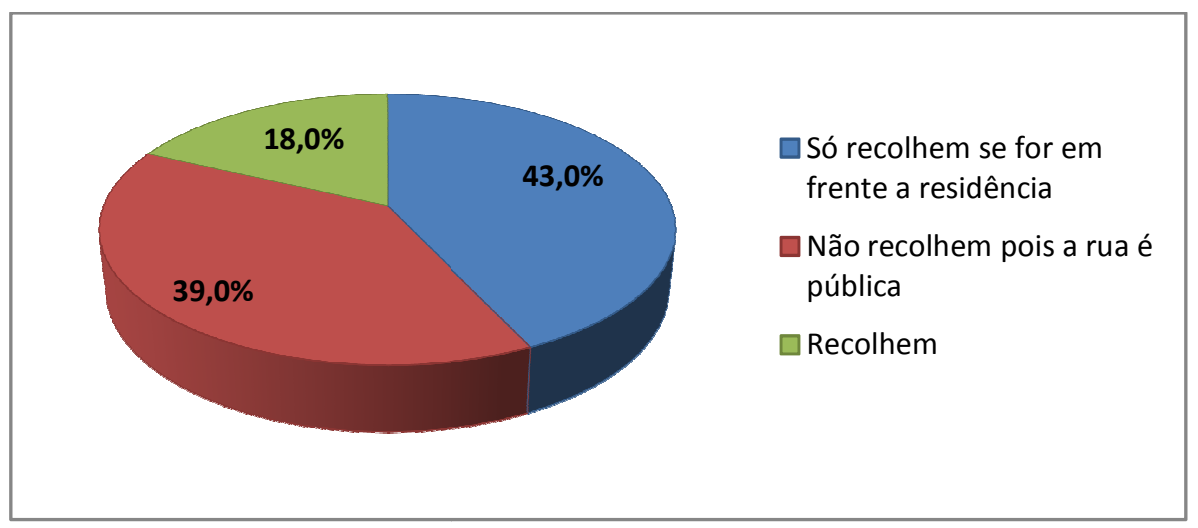

Figura 3 - Atitudes dos tutores quanto ao recolhimento de fezes dos animais deixadas na rua

Verifica-se, através dos resultados, que os tutores mostram irresponsabilidade em relação ao meio ambiente e saúde pública, pois a grande maioria afirma que os animais defecam nas ruas e apenas uma minoria se preocupa em recolher as fezes. Em pesquisa realizada nos Estados Unidos da América, Faulkner $(1975)^{12}$ estimou que os cães produzissem 3.5 mil toneladas de fezes e 36 milhões de litros de urina diariamente. Os dejetos no ambiente provêem local de reprodução de moscas, alimento para roedores e fonte de contaminação para água e alimentos por patógenos zoonóticos (Carter, 1990 $)^{13}$. Em uma pesquisa realizada por Scaini et al. (2003) ${ }^{14}$ com amostras de fezes retiradas das ruas do Balneário Cassino no Rio Grande do Sul foi 
SOUSA, M.R.Q. e SILVA, F.B.S. Interação homem-animal e sua relação com a guarda responsável de cães em um bairro da cidade do Recife-PE. PUBVET, Londrina, V. 6, N. 5, Ed. 192, Art. 1294, 2012.

constatado que $86,1 \%$ apresentaram positividade para ovos e/ou larvas de helmintos.

Dentre as zoonoses que podem ser transmitidas pelas fezes, destaca-se a ancilostomíase devido a sua alta ocorrência nos cães. É uma zoonose que, no homem é responsável, na maioria dos casos, pela lesão cutânea denominada Larva Migrans Cutânea ou "bicho-geográfico". Diversas pesquisas realizadas em fezes de cães recolhidas de locais públicos encontraram um percentual alto de positividade para Ancylostoma sp (Nunes et al. (2004) ${ }^{15}$; Pereira et al $(2005)^{16}$; Silva et al $(2007)^{17}$; Campos-Filho et al $\left.(2008)^{18}\right)$.

Considerando o aumento da população de animais de companhia que ocorreu nos últimos anos e que o Brasil ocupa o segundo lugar no número de cães, entende-se que deve haver uma preocupação das autoridades em implantar programas de educação em guarda responsável.

Diversos fatores contribuem para o aumento da população de cães errantes, sendo a falta de controle da reprodução dos mesmos aquele de maior impacto. Dentre os métodos contraceptivos, a castração cirúrgica é o mais seguro e eficaz. Entretanto, este método é cercado de tabus por parte da população leiga. É comum as pessoas afirmarem que se faz necessário que as fêmeas tenham, pelo menos, uma cria antes de ser submetida a castração e, no caso dos machos, diversos tabus antropomórficos são utilizados para justiçar a não castração dos mesmos, tais como, a frustração do animal por não poder cruzar e sentir prazer.

Os resultados (tabela 1) mostram que $\mathbf{9 8 . 0 \%}$ dos tutores afirmaram não ter castrado seus animais. É um dado bastante preocupante, uma vez que não há controle eficiente do acesso dos animais as ruas, o que aumenta a probabilidade de cruzamentos. Entretanto, devemos considerar, também, que o termo castração é de conhecimento popular como sendo restrito aos machos, o que pode ter influenciado os resultados. Como conseqüência deste comportamento, diversos filhotes são abandonados todos os dias em locais públicos ou ainda submetidos a atos de crueldade, como ser jogados no lixo ou mortos. 
SOUSA, M.R.Q. e SILVA, F.B.S. Interação homem-animal e sua relação com a guarda responsável de cães em um bairro da cidade do Recife-PE. PUBVET, Londrina, V. 6, N. 5, Ed. 192, Art. 1294, 2012.

Verificou-se que $90,0 \%$ dos entrevistados afirmaram estar dispostos a cuidar dos animais até o final de suas vidas. Apesar deste resultado animador, a realidade dos animais que são abandonados não retrata esta tendência. 0 que se verifica são animais idosos e/ou doentes, sendo deixados pelos seus donos em locais públicos por motivos variados, que incluem falta de condições financeiras para cuidar e tratar dos mesmos.

Quando os tutores foram questionados sobre o que fariam quando os animais ficassem idosos e/ou doentes (figura 4), verificou-se que 13,0\% assumiram que chamariam a "Carrocinha" para recolher seu animal. Nascimento et al. $(2008)^{19}$ em pesquisa realizada na cidade do Recife, verificaram que aproximadamente $70,0 \%$ dos entrevistados tem conhecimento de que o destino da maioria dos animais recolhidos pelos Centros de Controle de Zoonose é a eutanásia.

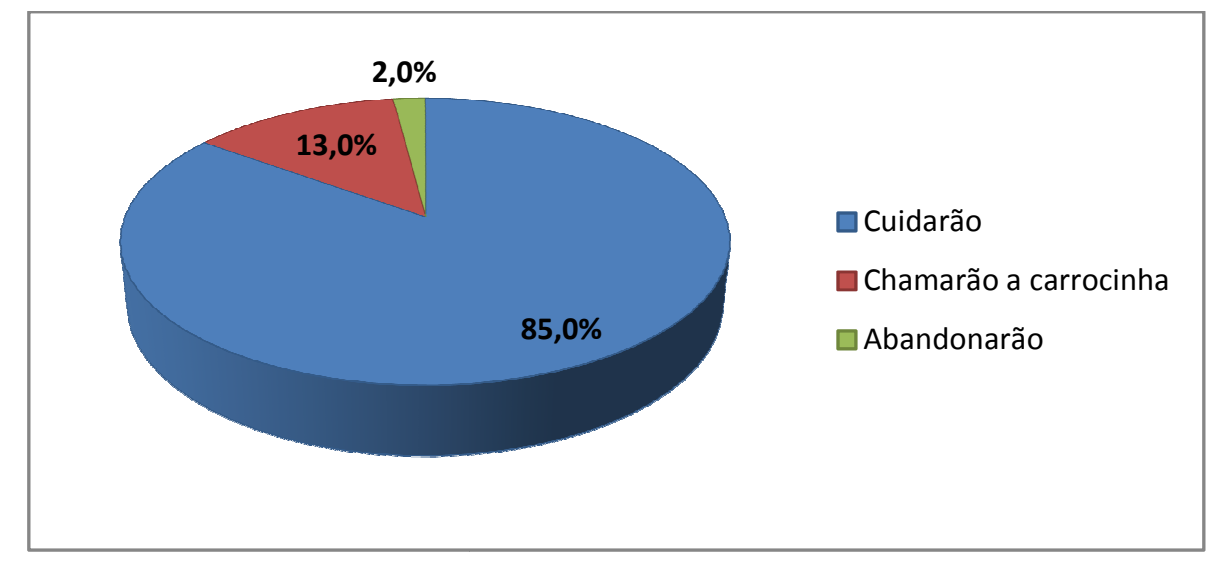

Figura 4 - Possíveis atitudes dos tutores quando os seus animais ficarem idosos e/ou doentes

Quanto à possibilidade dos animais poderem transmitir doenças, verificou-se que apenas 3,0\% dos entrevistados afirmaram conhecer o termo zoonose, entretanto $81.0 \%$ tem conhecimento da possível transmissão de doenças pelos animais, tendo sido citadas a raiva $(74,0 \%)$, verminoses $(6,0 \%)$ e leishmaniose $(1,0 \%)$. Este achado nos alerta para a necessidade de se utilizar uma linguagem menos técnica, quando se pretendo trabalhar com 
SOUSA, M.R.Q. e SILVA, F.B.S. Interação homem-animal e sua relação com a guarda responsável de cães em um bairro da cidade do Recife-PE. PUBVET, Londrina, V. 6, N. 5, Ed. 192, Art. 1294, 2012.

conscientização da população para guarda responsável e educação em saúde pública, especialmente através dos meios de comunicação, e por abordagens diretas nas comunidades. A raiva também foi a zoonose mais citada durante uma pesquisa feita por Barros et al. $(2009)^{20}$ em Recife-PE o que, provavelmente está relacionado a ampla divulgação das campanhas de vacinação.

Através desta pesquisa, pode-se constatar que há necessidade de programas oficiais de educação em guarda responsável que, além de melhorar a interação homem-animal, contribuirá para melhoria do bem-estar dos animais de companhia e da saúde pública em geral.

\section{AGRADECIMENTO}

Agradecemos aos tutores dos animais pela disponibilidade de participar da pesquisa e aos Agentes Comunitários de Saúde da Prefeitura do Recife pela colaboração na pesquisa e na orientação dos propietários.

\section{REFERÊNCIAS}

1- http://www.mapsofworld.com/world-top-ten/countries-with-most-pet-dogpopulation.html. Acesso 18 de julho de 2011.

2- Aliança ICAM. Guia de controle humanitário da população canina. 2007, 24p.

3- WHO. WSPA. World Health Organization World Society for the protection of animals. Guidelines for dog population management. Geneva, 1990. 116p.

4- http://www.oie.int/eng/normes/MCODE/en_chapitre 1.7.7.pdf. Acesso em 11 de agosto de 2010.

5- LUNA, S. P. L. Controle populacional de cães e gatos. Você é um proprietário de cães e gatos responsável? http://www.botucatu.sp.gov.br/artigos/artigos/castracao animais.pdf. Acesso em 08 de julho de 2009.

6- http://www.recife.pe.gov.br/pr/secplanejamento/inforec/bairros.php Acesso em 14 de julho de 2011.

7- PINHEIRO JR, O.A.; SILVA, M.O.C.; ANGELA, H.R. et. al. Posse responsável de cães e gatos no município de Garça/SP. Revista científica eletrônica de medicina veterinária, Ano III, N. 06, Janeiro de 2006

8- SILVA, F.A.N.; CARVALHO, R.L.; KLEIN, R.P.; QUESSADA, A.M.. Posse responsável de cães no bairro Buenos Aires na cidade de Teresina (PI). Ars Veterinária, v.25, n.1. p.14-17, 2009. 
9- FARACO, C.B. Interação humano-animal. Ciênc. Vet. Tróp., Recife-PE, v. 11, suplemento 1, p. 31-35 abril, 2008.

10- SALZO, P.S.; LARSSON, C.E. Hipersensibilidade alimentar em cães. Arq. Bras. Med. Vet. Zootec., v.61, n.3, p.598-605, 2009.

11- CUNHA, M. C. M.; DUARTE, R.M.; SILVA, D. A. Conhecimentos, atitudes e práticas de moradores de um bairro de Betim (MG) sobre bem-estar animal, controle de zoonoses e adesão aos programas públicos de controle populacional de cães.

http://www.pucminas.br/seminarioprograd/iv seminario/pdfs/puc mor betim.pdf.

Acesso em 30 de junho de 2011.

12- FAULKNER, L.C. Dimensions of pet population problem. J. Am. Vet. Med. Assoc. v. 199, n.1, p. 477-478, 1975.

13- CARTER, C.N. Pet population control: another decade without solutions? J. Am. Vet. Med. Assoc. v.197, n.2, p. 192-195, 1990.

14- SCAINI, C.J.; TOLEDO, R.N.; LOVATEL, R. et al. Contaminação ambiental por ovos e larvas de helmintos em fezes de cães na área central do Balneário Cassino, Rio Grande do Sul. Revista da Sociedade Brasileira de Medicina Tropical, v.36, n.5, p.617$619,2003$.

15- NUNEZ, M.V; PORTALEONI, F.; CERTO, C.M.G.; RODRIGUES, A.C. Levantamento parasitológico em cães (Canis familiaris) domiciliados e semi domiciliados no município de Peruíbe, Baixada Santista. In: Reunião Anual do Instituto Biológico, XVII. São Paulo. Resumos... Arq Inst Biol. 2004; 71(supl.):70-70.

16- PEREIRA, C.E.M.; FONTOURA, M.F.G.; SOUZA, P.A.; RODRIGUES, A.C. Ocorrência de ovos e oocistos de parasitas gastrointestinais nas fezes de cães (Canis familiaris) recolhidas em vias públicas no bairro Jockey Club, município de São Vicente, São Paulo, Brasil. In: 30 Congresso de Iniciação Científica em Ciências agrárias, Biológicas e Ambientais. São Paulo. Arq Inst Biol. 2005; 72(supl.1):39-39.

17- SILVA, A. S.; CEOLIN, L. V.; CARGNELUTTI, J. F. et al. Prevalência de parasitismo em cães domiciliados num bairro de Santa Maria - RS. Saúde, Santa Maria, vol 33, n 1: p 27-31, 2007.

18- CAMPOS FILHO, P. C.; BARROS, L.M.; CAMPOS, J. O. et al. Parasitas zoonóticos em fezes de cães em praças públicas do município de Iabuna, Bahia, Brasil. Rev. Bras. Parasitol. Vet., 17, 4, 206-209, 2008. - 48\% das amostras foram positivas para Ancylostoma sp.

19- NASCIMENTO, M. C.O.; CARVALHO, J. N.; LIMA, R. M. et al. Concepções sobre a carrocinha pelos visitantes da $66^{\text {a }}$ Exposição Nordestina de Animais e Produtos Derivados. I Congresso Brasileiro de Bioética e Bem-Estar Animal e I Seminário Nacional de Biossegurança e Biotecnologia Animal. p.12, 2008, Recife

20- BARROS, M.B.S.; SILVA, L.G.; NUNES JUNIOR, F.P. et al. Percepção dos visitantes da 66a Exposição Nordestina de Animais e Produtos Derivados sobre zoonoses transmitidas por cães e gatos. PUBVET, Londrina, V.3, N.4. Art\#495, Fev 1, 2009. 